\title{
Pesquisa de Salmonella e Outras Enterobactérias Nas Etapas de Pós-Colheita do Amendoim
}

Angélica Bernardi (I), Dennis Henrique da Silva (I), Izabel da Silva (I), Eduardo Duarte (I), Maristela Nascimento (I)

(I) ITAL - Instituto de Tecnologia de Alimentos (Av. Brasil 2880, Campinas/SP, Brasil, 13070178)

\section{Resumo}

Devido aos recentes surtos, o amendoim tem sido considerado um produto de risco potencial para Salmonella. Contudo, ainda são poucas as informações de literatura sobre Salmonella nas etapas de colheita e póscolheita do amendoim. O objetivo desse trabalho foi investigar a presença de enterobactérias, coliformes, Escherichia coli e Salmonella nas etapas que antecedem o beneficiamento do amendoim. Foram analisadas 63 amostras de produtores dos Estados de São Paulo (30), Minas Gerais (20) e Bahia (13) envolvendo as etapas de arranquio do solo, enleiramento e despencamento da planta. A pesquisa de Salmonella foi realizada em $250 \mathrm{~g}$ de amostra por método de imunoensaio, utilizando o sistema Mini-Vidas. Para a análise de enterobactérias, utilizou-se o meio de cultura Ágar Vermelho Violeta Bile com Glicose (VRBG) e para contagem de coliformes totais e E. coli, Petrifilm. Além das análises microbiológicas também foram verificados o $\mathrm{pH}$ e a atividade de água (aw) das amostras. A aw reduziu de 0,99 imediatamente após o arranquio para 0,97 durante o enleiramento e 0,88 após o despencamento. Para o pH não foi verificada diferença significativa entre as amostras das diferentes etapas avaliadas $(6,23$ a 6,57). Com relação às análises microbiológicas, as amostras apresentaram altas contagens de enterobactérias, 6,62 a 8,46 log UFC/g na etapa de arranquio, 5,18 a 8,36 log UFC/g no enleiramento e 7,31 a 8,82 $\log$ UFC/g no despencamento. A etapa de enleiramento apresentou as menores contagens de coliformes totais (3,68 e 6,01 log UFC/g) seguida 
pelo despencamento (4,32 a 6,33 log UFC/g) e arranquio (5,38 e 6,82 log UFC/g). Duas amostras apresentaram contaminação por E. coli, sendo uma amostra da etapa de enleiramento (2 log UFC/g) e uma da etapa de despencamento (4 log UFC/g). Cinco amostras (7,9\%) apresentaram contaminação por Salmonella, sendo uma amostra da etapa de arranquio de $\mathrm{SP}(0,064 \mathrm{NMP} / \mathrm{g})$ e quatro da etapa de despencamento (uma de SP - 0,004 $\mathrm{NMP} / \mathrm{g}$ e três de MG - 0,037 a 0,092 NMP/g). Os resultados obtidos demonstram que pode haver contaminação do amendoim por Salmonella antes do seu beneficiamento, isto reforça a importância do emprego de programas de boas práticas agrícolas e de fabricação para prevenir possíveis contaminações do produto final.

Palavras-Chave: Salmonella, amendoim, enterobactérias Agência de Fomento: Fapesp 